\title{
DETERMINAÇÃO DAS PROPRIEDADES CATALÍTICAS EM MEIO AQUOSO E ORGÂNICO DA LIPASE DE Candida rugosa IMOBILIZADA EM CELULIGNINA QUIMICAMENTE MODIFICADA POR CARBONILDIIMIDAZOL
}

\author{
Fabrício M. Gomes, Ariela V. de Paula, Grazielle dos S. Silva e Heizir F. de Castro* \\ Departamento de Engenharia Química, Faculdade de Engenharia Química de Lorena, CP 116, 12606-970 Lorena - SP, Brasil
}

Recebido em 11/5/05; aceito em 27/10/05; publicado na web em 31/3/06

\begin{abstract}
ASSESSMENT OF CATALYTIC PROPERTIES IN AQUEOUS AND ORGANIC MEDIA OF LIPASE FROM Candida rugosa IMMOBILIZED ON WOOD CELLULIGNIN ACTIVATED WITH CARBONYLDIIMIDAZOLE. Microbial lipase from Candida rugosa was immobilized by covalent binding on wood cellulignin (Eucaliptus grandis) chemically modified with carbonyldiimidazole. The immobilized system was fully evaluated in aqueous (olive oil hydrolysis) and organic (ester synthesis) media. A comparative study between free and immobilized lipase was carried out in terms of $\mathrm{pH}$, temperature and thermal stability. A higher $\mathrm{pH}$ value (8.0) was found optimal for the immobilized lipase. The optimal reaction temperature shifted from $37{ }^{\circ} \mathrm{C}$ for the free lipase to $45{ }^{\circ} \mathrm{C}$ for the immobilized lipase. The pattern of heat stability indicated that the immobilization process tends to stabilize the enzyme. Kinetics tests at $37^{\circ} \mathrm{C}$ following the hydrolysis of olive oil obeyed the Michaelis-Menten rate equation. Values for $K_{m}=924.9 \mathrm{mM}$ and $V_{\max }=198.3 \mathrm{U} / \mathrm{mg}$ were lower than for free lipase, suggesting that the affinity towards the substrate changed and the activity of the immobilized lipase decreased during the course of immobilization. The immobilized derivative was also tested in the ester synthesis from several alcohols and carboxylic acids.
\end{abstract}

Keywords: cellulignin; lipase; immobilization.

\section{INTRODUÇÃO}

Os processos que utilizam lipases são especialmente atraentes em função das diferentes aplicações desta enzima. As lipases podem catalisar reações de hidrólise, esterificação e interesterificação, com extrema simplicidade de processo, qualidade superior do produto final e excelente rendimento ${ }^{1-3}$. Estas características conferem às lipases um potencial biotecnológico comparável ao das proteases e carboidrases - enzimas industrialmente utilizadas - estimulando pesquisas para otimização da sua produção, caracterização, imobilização e aplicação industrial ${ }^{2,3}$.

Idealmente os sistemas catalisados por lipases devem ser tratados caso a caso e as generalizações devem ser praticadas com cautela $^{2}$. Portanto, a seleção das condições adequadas na catálise enzimática em meios não convencionais deve seguir uma cuidadosa manipulação do meio-ambiente do biocatalisador, de tal forma que a produtividade do sistema seja maximizada por meio da potencialidade total da atividade enzimática ${ }^{2}$. Isto pode ser alcançado pela utilização de solventes apropriados ${ }^{4,5}$, controle do teor de água no meio reacional ${ }^{6,7}$ e imobilização da enzima em suportes sólidos ${ }^{8-10}$. A imobilização tem efeito benéfico na estabilidade da enzima, em função das interações físicas e químicas entre o suporte e as moléculas da enzima. A imobilização também auxilia na dispersão homogênea da enzima no meio, o que é essencial para a condução de reações enzimáticas ${ }^{9,10}$.

As propriedades dos derivados imobilizados são influenciadas tanto pelas propriedades da enzima como pelo material do supor$\mathrm{te}^{2,11}$. A interação entre esses dois componentes proporciona um derivado imobilizado com propriedades químicas, bioquímicas, mecânicas e cinéticas específicas ${ }^{11,12}$. Dentre os vários parâmetros que devem ser considerados, os mais importantes são $\mathrm{pH}$, temperatura,

*e-mail: heizir@dequi.faenquil.br força iônica, pressão, agitação, liberação de cofatores e do substrato com a remoção dos produtos. Estes fatores influenciam no desempenho do suporte, na conformação da enzima, na velocidade de transferência de massa e de reação intrínseca e, portanto, afetam o comportamento da enzima imobilizada ${ }^{4,9,10}$.

De todos os fatores citados com exceção da enzima, a maior contribuição para o bom desempenho da enzima imobilizada é fornecida pelo suporte ${ }^{11,12}$. Se, por um lado, o suporte criteriosamente selecionado pode aumentar o tempo de meia-vida da enzima imobilizada, por outro, uma escolha imprudente pode afetar adversamente não só o tempo de meia-vida, mas o desempenho global do sistema ${ }^{2,12}$.

Uma grande variedade de materiais naturais, sintéticos, orgânicos ou inorgânicos com diferentes características, tamanho, forma e densidade, tem sido estudada para a imobilização de lipases ${ }^{8-10}$. Na sua maioria, utiliza suportes inorgânicos porosos de alto custo devido, em parte, a sua resistência ao ataque microbiano e grande área superficial disponível para ligação com a enzima. Entretanto, várias substâncias orgânicas, tais como celulose e seus derivados, são também dotadas de grande estabilidade física e resistência ao ataque por microrganismos.

A celulignina é o produto obtido na pré-hidrólise de biomassa em reatores revestidos com metais refratários, com médio poder calorífico e combustível catalítico que se destina à utilização em termoelétricas de ciclo combinado, gerando energia com custos inferiores aos da hidroelétrica (< US\$ 30,00/MWh) ${ }^{14}$. Devido ao seu alto grau de polimerização ( $35 \%$ lignina $+65 \%$ celulose) e propriedades físico-químicas como porosidade e área superficial, este material pode apresentar grande potencial para ser utilizado como matriz de imobilização de catalisadores químicos e bioquímicos.

Em trabalhos anteriores ${ }^{15,16}$, a celulignina foi testada com sucesso como matriz de imobilização da lipase microbiana (lipase de Candida rugosa) empregando hexano como meio de dispersão. Entre as técnicas de imobilização testadas (adsorção física e liga- 
ção covalente) os resultados mais elevados foram obtidos para a metodologia de imobilização por ligação covalente empregando celulignina quimicamente modificada com carbonildiimidazol. Esta técnica forneceu derivados imobilizados mais ativos $(152 \mathrm{U} / \mathrm{mg}$ ) em relação aos obtidos empregando celulignina in natura ou modificada com glutaraldeído ${ }^{16}$.

A utilização do carbonildiimidazol (CDI) na modificação química de suportes contendo grupos hidroxilas para imobilização de enzimas tem apresentado resultados satisfatórios ${ }^{17}$. O CDI atua como um agente carbonilante, inserindo uma carbonila no suporte (Esquema 1). A reação deve ser feita com uma solução de CDI em solvente polar aprótico ${ }^{18}$. No contato do suporte com a solução enzimática, o nitrogênio nucleofílico do grupo amino livre da enzima ataca a carbonila presente no suporte modificado, ocorrendo a ligação covalente entre a enzima e o $\operatorname{suporte}^{17}$ (Esquema 2).

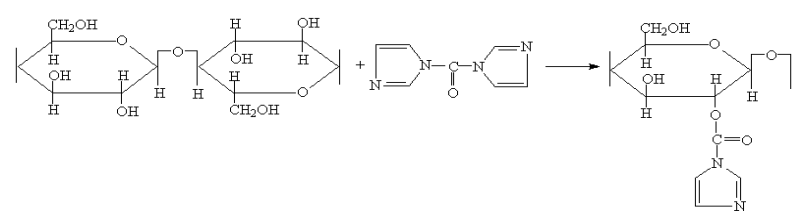

Esquema 1. Reação de carbonilação da celulose com carbonildiimidazol

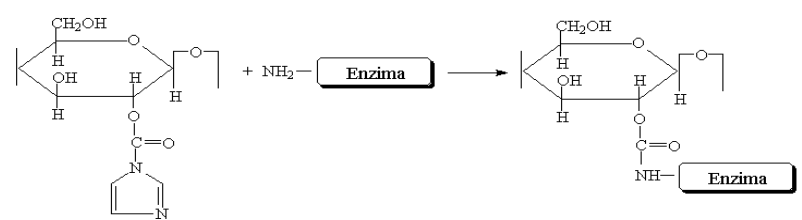

Esquema 2. Ligação covalente da enzima com celulose quimicamente modificada com carbonildiimidazol

Considerando o bom desempenho da celulignina como matriz de imobilização da lipase de Candida rugosa ${ }^{16}$, julgou-se conveniente um estudo mais detalhado referente à aplicação do sistema imobilizado resultante em reações típicas catalisadas por lipases. Em meio aquoso, as características bioquímicas, cinéticas e catalíticas do sistema imobilizado foram determinadas na reação de hidrólise do azeite de oliva. Em meio orgânico, adotou-se como modelo de estudo a reação de esterificação de álcoois primários com ácidos carboxílicos em heptano como solvente. Os dados obtidos foram comparados com os descritos na literatura referentes à caracterização da lipase de Candida rugosa imobilizada em diferentes suportes orgânicos e inorgânicos.

\section{PARTE EXPERIMENTAL}

\section{Materiais}

A lipase microbiana (Candida rugosa, tipo VII) foi adquirida da Sigma Chemicals Co. (St. Louis, MO, EUA), com atividade específica média de $1870 \mathrm{U} / \mathrm{mg}$ de proteína (hidrólise do azeite de oliva). Como matriz de imobilização foi empregada celulignina de madeira (Eucalyptus grandis), obtida pelo craqueamento da madeira por hidrólise ácida, gentilmente cedida pelo Departamento de Engenharia de Materiais - FAENQUIL, com as seguintes características ${ }^{14}$ : estrutura porosa, $35 \%$ de lignina, $65 \%$ celulose, granulometria 80 a 100 mesh; densidade $0,35 \mathrm{~g} / \mathrm{cm}^{3}$. Para os testes catalíticos foram usados azeite de oliva comercial de baixa acidez (Carbonell), ácidos carboxílicos (butírico, octanóico e láurico) e álcoois primários (etanol, propanol, butanol, hexanol e octanol) adquiridos da Merck ou Vetec. Os ésteres utilizados como padrões cromatográficos foram sintetizados por via química no Laboratório de Síntese Orgânica - FAENQUIL, com estrutura comprovada por RNM de próton $\left(\mathrm{CDCl}_{3}, \delta, 300 \mathrm{~Hz}\right)$. Todos os outros reagentes foram de grau analítico.

\section{Imobilização da lipase em celulignina}

Em um procedimento típico, o suporte foi inicialmente neutralizado por meio da adição de uma solução de hidróxido de sódio $(0,1 \mathrm{M})$ e, em seguida, tratado com carbonildiimidazol diluído em dimetilsulfóxido $(5 \mathrm{mg} / \mathrm{mL})^{16,17}$. O procedimento de imobilização consistiu do contato da solução enzimática (250 U) com o suporte previamente umedecido com hexano na presença de polietilenoglicol (PEG, MM 1500), por um período total de $21 \mathrm{~h}$. A enzima imobilizada foi recuperada por filtração a vácuo (papel de filtro Whatman $n^{\circ} 41$ ) e o sistema lavado com hexano gelado para redução do teor de água. Nessas condições ${ }^{16}$, derivados imobilizados com elevada atividade hidrolítica (substrato azeite de oliva) foram obtidos (193 U/mg), correspondendo a uma recuperação de atividade da ordem de $64 \%$.

\section{Propriedades catalíticas da lipase livre e imobilizada em meio aquoso}

A atividade enzimática da lipase nas formas livre e imobilizada foi determinada pelo método de hidrólise do azeite de oliva, conforme metodologia modificada por Soares et al ${ }^{19}$. O substrato foi preparado pela emulsão de $50 \mathrm{~mL}$ de azeite de oliva e $50 \mathrm{~mL}$ de goma arábica a $7 \%(\mathrm{~m} / \mathrm{v})$. Em frascos Erlenmeyer de $125 \mathrm{~mL}$ foram adicionados $5 \mathrm{~mL}$ de substrato, $4 \mathrm{~mL}$ de solução tampão fosfato de sódio $(0,1 \mathrm{M}, \mathrm{pH} 7,0)$ e $1 \mathrm{~mL}$ da solução enzimática $(5 \mathrm{mg} / \mathrm{mL})$ ou cerca de $100 \mathrm{mg}$ de lipase imobilizada (massa seca). Os frascos foram incubados a $37{ }^{\circ} \mathrm{C}$ por $5 \mathrm{~min}$, em banho termostatizado com agitação. Após o período de incubação, a reação foi paralisada pela adição de $10 \mathrm{~mL}$ de uma mistura de acetona e etanol (1:1). Os ácidos graxos liberados foram titulados com solução padronizada de $\mathrm{KOH} 20$ mM, utilizando fenolftaleína como indicador. Uma unidade de atividade foi definida como a quantidade de enzima que libera em $1 \mu \mathrm{mol}$ de ácido graxo por min de reação, nas condições do ensaio. As atividades foram expressas em ( $\mu$ moles/mg min) (U), sendo que mg refere-se à massa de sólido para a lipase livre e suporte seco para a lipase imobilizada. Adotando-se esse procedimento, foi determinada a influência do $\mathrm{pH}(5,0-9,0)$, temperatura $\left(40-60{ }^{\circ} \mathrm{C}\right.$ ) e concentração do substrato (emulsão $10-50 \%$ ) nas atividades da lipase nas formas livre e imobilizada. Os valores de $K_{m}$ e $V_{\max }$ aparentes foram calculados com o auxílio do Programa Enzyme Fitter. A constante de inativação térmica $\left(k_{d}\right)^{11}$ para a lipase livre e imobilizada foi calculada pela Equação 1

$\ln \frac{A_{\text {in }}}{A_{\text {in } 0}}=K_{d} \cdot t$

sendo, $\mathrm{A}_{\text {in }}=$ atividade residual após tratamento térmico durante um certo período de incubação, $\mathrm{A}_{\mathrm{in} 0}=$ atividade enzimática inicial.

\section{Procedimento das reações de esterificação}

As reações de esterificação foram conduzidas em reatores fechados de $100 \mathrm{~mL}$, contendo $20 \mathrm{~mL}$ de heptano previamente desidratado com sódio metálico e quantidades equimolares dos diferentes álcoois (etanol, propanol, butanol, hexanol e octanol) e ácidos carboxílicos (butírico, octanóico e láurico). As misturas foram 
incubadas com a lipase imobilizada $(150 \mathrm{U} / \mathrm{mg})$ em uma proporção de $10 \%(\mathrm{~m} / \mathrm{v})$ em relação à massa total de reagentes no meio reacional. Todas as reações foram realizadas a $37^{\circ} \mathrm{C}$, sob agitação constante de $150 \mathrm{rpm}$, por um período máximo de $48 \mathrm{~h}$. Alíquotas de $1 \mathrm{~mL}$ foram retiradas do meio reacional em intervalos de tempo pré-estipulados, para se determinar a concentração dos materiais de partida consumidos e os produtos formados.

\section{Métodos analíticos}

A concentração de ácido carboxílico foi determinada por titulação de alíquotas coletadas da reação e dissolvidas em $10 \mathrm{~mL}$ de etanol $98^{\circ}$ GL neutralizado, empregando-se solução alcoólica padronizada de $\mathrm{KOH}$ 0,02 M e fenolftaleína como indicador. As concentrações dos álcoois e ésteres foram quantificadas por cromatografia em fase gasosa (Cromatógrafo Varian CG 3800), empregando uma coluna de $6 \mathrm{ft}$ de comprimento empacotada com 5\% DEGS em Chromosorb WHP 80/10 mesh (Hewlett Packard, EUA) e nitrogênio (30 $\mathrm{mL} / \mathrm{min}$ ) como gás de arraste. Para os compostos butanol e butirato de butila, a coluna foi mantida a $75^{\circ} \mathrm{C}$ e empregou-se hexanol como padrão interno. Para os compostos octanoato de butila e laurato de butila empregou-se octanol como padrão interno e a coluna foi mantida a $130{ }^{\circ} \mathrm{C}$. O grau de esterificação foi expresso em percentual molar do álcool consumido, empregando a Equação 2

$$
\% \text { molar }=\frac{C_{0}-C}{C_{0}} \times 100
$$

sendo, $\mathrm{C}_{0}=$ concentração inicial do álcool e $\mathrm{C}=$ concentração do álcool em um determinado tempo.

\section{Testes de estabilidade}

\section{Estabilidade de estocagem}

Uma certa massa de amostra do derivado imobilizado foi estocada a $4{ }^{\circ} \mathrm{C}$ por um período máximo de 90 dias e a atividade hidrolítica residual, quantificada em intervalos de tempo de 30 dias. Os resultados foram expressos em porcentagem de atividade perdida.

\section{Estabilidade térmica}

As reações de hidrólise foram realizadas por meio da incubação de diversas amostras da lipase livre $(1 \mathrm{~mL}, 5 \mathrm{mg} / \mathrm{mL})$ e imobilizada (100 mg) em uma faixa de temperatura de $40-60{ }^{\circ} \mathrm{C}$ em solução aquosa de tampão fosfato $(0,1 \mathrm{M} ; \mathrm{pH}=7,0$ para lipase livre e $\mathrm{pH}=8,0$ para lipase imobilizada) durante $60 \mathrm{~min}$. Após o tratamento térmico, as amostras foram imediatamente resfriadas em banho de gelo para interromper a reação de inativação e, em seguida, a atividade residual foi determinada a $37{ }^{\circ} \mathrm{C}$, pela adição de $5 \mathrm{~mL}$ de emulsão de azeite de oliva em uma proporção de $50 \%$ $(\mathrm{m} / \mathrm{v})$ e o tempo de meia-vida $\left(\mathrm{t}_{1 / 2}\right)$ foi calculado pela Equação 3

$\mathrm{t}_{1 / 2}=\frac{0,693}{K d}$

sendo, $\mathrm{k}_{\mathrm{d}}=$ constante de desativação.

\section{Estabilidade operacional}

A estabilidade operacional do sistema imobilizado foi verificada em reações de hidrólise e síntese de ésteres em regime de bateladas consecutivas com a reutilização do sistema imobilizado. As reações de hidrólise foram realizadas empregando-se uma emulsão de azeite de oliva em uma proporção de $50 \%(\mathrm{~m} / \mathrm{v})$ e $0,5 \mathrm{~g}$ da amostra de lipase imobilizada $\left(30 \mathrm{~min} / 37^{\circ} \mathrm{C}\right)$. As reações de síntese foram realizadas em frascos fechados de $100 \mathrm{~mL}$, contendo $20 \mathrm{~mL}$ de substrato constituído de ácido octanóico e butanol em concentrações equimolares $(250 \mathrm{mmol})$ em meio a solvente (heptano) e utilizando-se $0,5 \mathrm{~g}$ de lipase imobilizada (massa seca). As bateladas consecutivas $\left(48 \mathrm{~h} / 37^{\circ} \mathrm{C}\right)$ foram monitoradas nos tempos inicial e final. Ao final de cada ciclo, foi analisado o teor de produto formado (ácidos graxos totais ou éster, dependendo do tipo de reação). O tempo de meia-vida foi calculado pela Equação 3.

\section{RESULTADOS E DISCUSSÃO}

Devido a sua natureza protéica, as enzimas são altamente sensíveis a variações de $\mathrm{pH}$, temperatura, concentração da própria enzima, entre outros fatores. Portanto, o conhecimento desses parâmetros sobre a reação enzimática permite explorar melhor as propriedades catalíticas.

Qualquer que seja o método de imobilização de enzimas desejase preservar, tanto quanto possível, a atividade biocatalítica e a especificidade. Apesar da superioridade das enzimas imobilizadas sobre as livres, o processo de imobilização pode modificar a cinética e as propriedades físico-químicas da enzima, normalmente, reduzindo a atividade específica. As modificações das propriedades enzimáticas devem-se aos seguintes fatores ${ }^{11}$ : efeitos conformacionais - modificação conformacional da molécula da enzima devido à alteração na estrutura terciária do sítio ativo; efeitos estereoquímicos uma parte da molécula da enzima é imobilizada em uma posição tal que o sítio ativo é relativamente inacessível ao substrato; efeitos microambientais (efeitos de partição) - interações eletrostáticas entre suporte e substrato; neste caso, as condições do microambiente próximo à enzima são diferentes daquelas da solução reacional e, efeitos difusionais ou de transferência de massa - têm origem na resistência de difusão do substrato até o sítio catalítico da enzima, e do produto para a solução.

Para verificar as alterações causadas nas propriedades originais da lipase livre, foi determinada a influência do $\mathrm{pH}$ e da temperatura na atividade enzimática das lipases livre e imobilizada, bem como estimados os parâmetros cinéticos.

\section{Influência do pH}

A variação da atividade relativa em função do $\mathrm{pH}$ para as lipases livre e imobilizada em celulignina é apresentada na Figura 1. Observa-se que o processo de imobilização deslocou o $\mathrm{pH}$ ótimo da enzima livre $(\mathrm{pH}=7,0)$, para um valor de $\mathrm{pH}$ mais básico $(\mathrm{pH}=8,0)$. Esse comportamento pode estar relacionado com possíveis mudanças conformacionais da enzima ou alterações de concentração en-

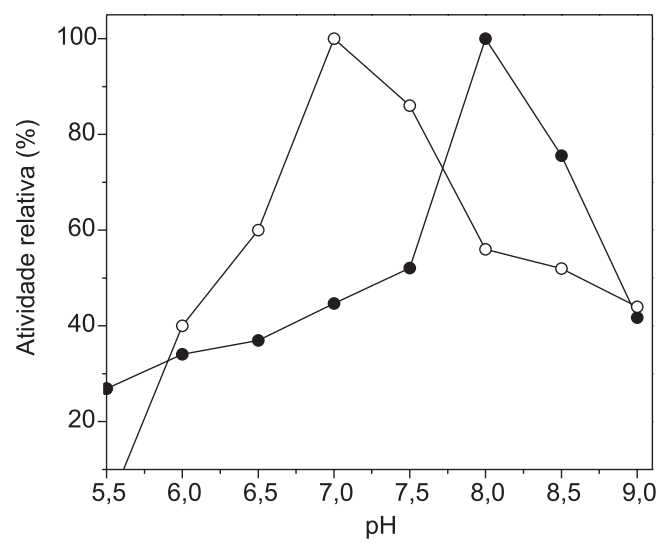

Figura 1. Influência do $\mathrm{pH}$ na atividade hidrolítica da lipase livre $(\bigcirc) e$ imobilizada em celulignina (-). Ensaio realizado a $37^{\circ} \mathrm{C}$ 
tre as espécies carregadas, substrato, produto, íons hidrogênio, íons hidroxilas, tanto no microambiente da enzima imobilizada quanto no meio reacional (macroambiente) $)^{11}$.

Normalmente, mediante imobilização, o pH ótimo de atuação da lipase modifica-se parcialmente para $\mathrm{pH}$ mais alcalino, tendo em vista que o ataque nucleofílico da serina é auxiliado pelo comportamento básico da histidina ${ }^{8,20}$. Em meios ácidos, estes grupos ficam protonados e o ataque nucleofílico da serina no grupo carbonílico do substrato (triglicerídeo) pode comprometer a formação do complexo acil-enzima. Os grupos hidroxilas $(-\mathrm{OH})$ presentes na estrutura do suporte possuem afinidade pelos hidrogênios ionizáveis $\left(\mathrm{H}^{+}\right)$disponíveis no meio reacional, ocasionando um acúmulo desses íons, o que pode afetar o microambiente da lipase e, conseqüentemente, sua faixa de $\mathrm{pH}$ ótimo de atuação ${ }^{11}$. Por outro lado, os grupos carboxílicos da lipase podem também influenciar o acúmulo de hidrogênios ionizáveis. A estabilização deste microambiente ocorre em $\mathrm{pH}$ básico, permitindo maior redução da concentração de $\mathrm{H}^{+}$no sistema imobilizado deslocando, por essa razão, o valor de $\mathrm{pH}$ ótimo de atuação da lipase de 7,0 na forma livre, para 8,0 na forma imobilizada. Entretanto, mudanças nos valores de $\mathrm{pH}$ ótimo de preparações de lipase imobilizada para valores mais ácidos foram descritas na literatura para a lipase de Candida rugosa imobilizada em quitosana ${ }^{21}$, um suporte catiônico. Nesse caso, o suporte agiu no sentido de ter mais íons com carga negativa nas proximidades da enzima, deslocando o perfil atividade- $\mathrm{pH}$ da enzima imobilizada para valores inferiores a $\mathrm{pH}=7,0$.

\section{Influência da temperatura}

A maioria das reações químicas se processa em uma velocidade maior à medida que a temperatura aumenta. Um aumento na temperatura imprime maior energia cinética às moléculas dos reagentes, ocasionando um maior número de colisões produtivas por unidade de tempo. As reações catalisadas por enzimas apresentam um comportamento semelhante às reações catalisadas quimicamente. Porém, as enzimas são moléculas protéicas complexas e sua atividade catalítica provém da necessidade de que sua estrutura terciária seja mantida, principalmente por um grande número de ligações não covalentes, como pontes de hidrogênio, ligações dissulfeto e interações hidrofóbicas ${ }^{2,8}$. Se a molécula absorve excesso de energia, a estrutura terciária se rompe e a enzima ficará desnaturada, perdendo sua atividade catalítica. À medida que a temperatura se eleva o aumento esperado na velocidade, resultante do aumento das colisões entre $\mathrm{E}+\mathrm{S}$, é contraposto pelo aumento da velocidade de desnaturação. Conseqüentemente, a curva de atividade-temperatura é o resultado líquido dos efeitos opostos resultantes da elevação da temperatura (aceleração da reação) e do aumento da inativação (desnaturação) ${ }^{11}$.

A dependência da temperatura na atividade enzimática foi investigada e os resultados obtidos são apresentados na Figura 2. Nota-se que a atividade máxima da lipase livre ocorreu a $37^{\circ} \mathrm{C}$, enquanto que a lipase imobilizada apresentou uma atividade máxima igual a $152,2 \mathrm{U} / \mathrm{mg}$ a $40{ }^{\circ} \mathrm{C}$. A partir dessa temperatura, a imobilização parece conferir alguma proteção à enzima, uma vez que a lipase imobilizada na temperatura de $50{ }^{\circ} \mathrm{C}$ apresentou maior atividade relativa que a lipase livre. Esses resultados sugerem que o processo de imobilização atuou no sentido de aumentar a temperatura ótima da enzima, o que é muito favorável, pois permite operações de trabalho em uma faixa maior de temperatura. $\mathrm{O}$ aumento da temperatura ótima de atuação da lipase imobilizada deve-se à ligação efetiva da enzima ao suporte, impedindo o desdobramento da estrutura terciária da enzima ${ }^{8,11}$.

$\mathrm{Na}$ literatura existem vários relatos de mudança na temperatura ótima de atuação da enzima mediante sua imobilização ${ }^{8}$.

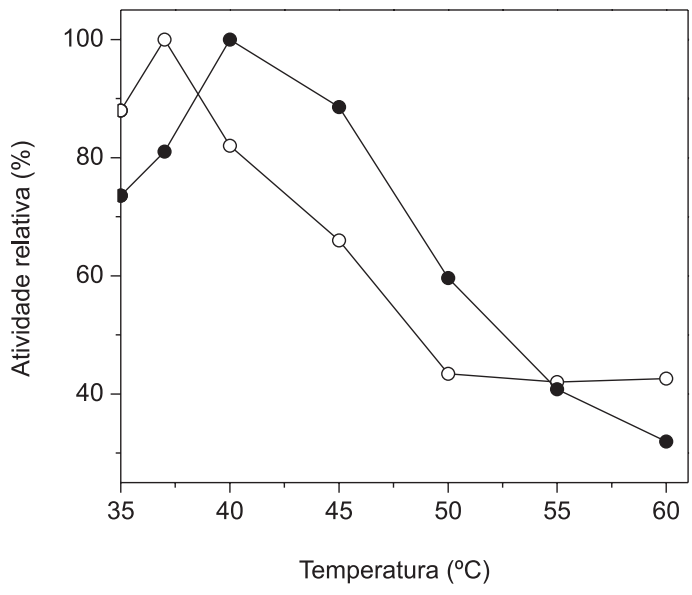

Figura 2. Influência da temperatura na atividade hidrolítica da lipase livre (O) e imobilizada em celulignina (

\section{Parâmetros cinéticos}

Nas Figuras 3 e 4 são apresentadas as atividades da lipase livre e imobilizada, respectivamente, em função da concentração de ácidos graxos presentes na emulsão óleo e água contendo diferentes proporções de azeite de oliva $(10-50 \% \mathrm{~m} / \mathrm{v})$. Os resultados obtidos sugerem que a atividade de ambas as formas de lipase (livre e imobilizada), em função da concentração de ácidos graxos, segue cinética do tipo Michaelis-Menten, indicando que na faixa de concentração estudada não se detectou uma possível inibição por produtos de reação ou pela redução do teor de água no meio reacional.

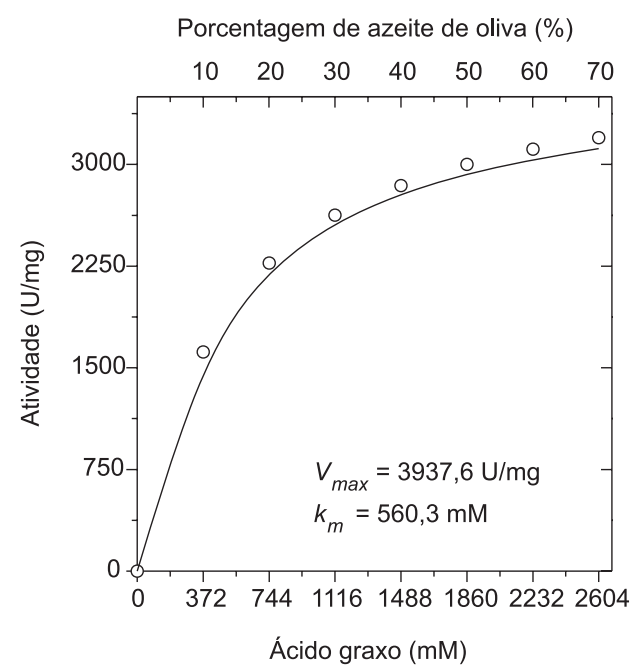

Figura 3. Atividade da lipase livre em função da concentração de ácidos graxos presentes nas emulsões óleo: água. Ensaios realizados em pH 7,0 a $37^{\circ} \mathrm{C}$

As constantes de afinidade pelo substrato $\left(K_{\mathrm{m}}\right)$ e a velocidade máxima de reação $\left(V_{\max }\right)$ foram calculadas com auxílio do programa Enzyme Fitter e os modelos propostos levaram aos resultados apresentados na Tabela 1 . O valor mais elevado de $K_{m}$ determinado para a lipase imobilizada indica que, mediante imobilização, a afinidade da lipase pelo substrato foi reduzida. Esse comportamento se deve à menor transferência de massa do meio reacional para o sistema imobilizado, pois o processo de imobilização reduz a difusão do substrato nos interstícios do suporte ${ }^{11}$.

Este é um perfil típico dos sistemas imobilizados, tendo em vista que a enzima livre exerce sua atividade catalítica em um meio 
Tabela 1. Equações, coeficientes de correlação do modelo linear invertido e constantes cinéticas para lipase livre e imobilizada

\begin{tabular}{|c|c|c|c|c|}
\hline Lipase & Equação & $K_{\mathrm{m}}(\mathrm{mM})$ & $V_{\max }(\mathrm{U} / \mathrm{mg})$ & $\mathrm{R}^{2}$ \\
\hline Livre & $y=0,2594+0,1364 x$ & 560,3 & 3937,6 & 0,984 \\
\hline Imobilizada & $y=0,0057+4,0525 x$ & 924,8 & 198,3 & 0,987 \\
\hline
\end{tabular}

em que: $\mathrm{y}=$ inverso da atividade $\left(\mathrm{mg} \mathrm{U}^{-1}\right) ; \mathrm{x}=$ inverso da concentração do substrato $\left(\mathrm{mM}^{-1}\right)$.

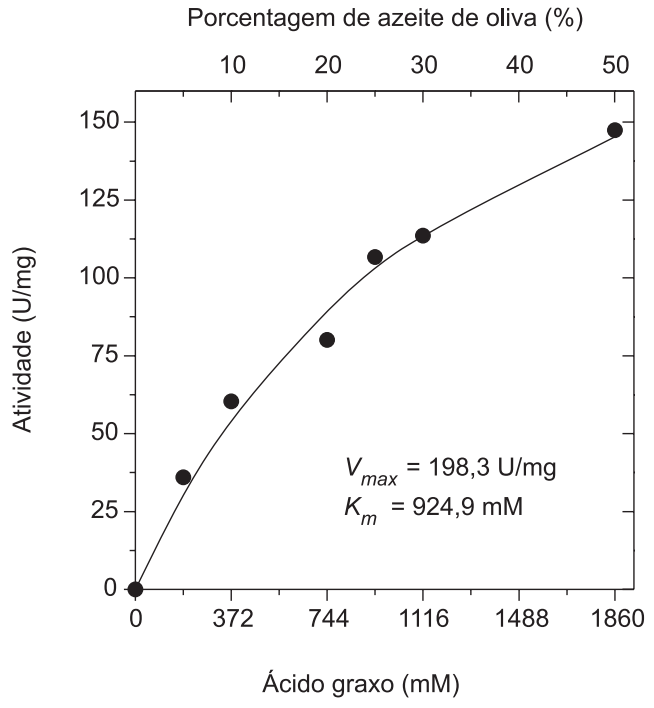

Figura 4. Atividade da lipase imobilizada em celulignina em função da concentração de ácidos graxos presentes nas emulsões óleo:água. Ensaios realizados em $\mathrm{pH} 8,0$ a $37^{\circ} \mathrm{C}$

homogêneo, enquanto a enzima imobilizada em um suporte sólido deve agir em um meio heterogêneo ${ }^{11}$. Desta forma, o decréscimo da atividade das enzimas imobilizadas pode ser normalmente atribuído às mudanças conformacionais na sua estrutura terciária ou aos impedimentos estéricos que resultam na dificuldade de acesso do substrato ao sítio ativo da enzima ${ }^{11}$.

No caso das lipases, um cuidado rigoroso deve ser tomado na aquisição desses dados cinéticos em sistemas emulsificados que, devido a sua elevada viscosidade, é um outro fator de restrição do acesso do substrato ao sítio ativo da enzima ${ }^{8}$. Observações de dados descritos na literatura indicam uma redução nos valores de $K_{m}$ para a lipase imobilizada da ordem de $50 \%$ em relação ao valor determinado para a lipase em sua forma livre ${ }^{8}$.

\section{Síntese de ésteres}

A influência do tamanho da cadeia do ácido carboxílico na conversão do butanol aos ésteres correspondentes foi determinada pela incubação do $n$-butanol e diversos ácidos carboxílicos (ácido butírico, octanóico e láurico) em uma razão molar fixa (1:1), com lipase imobilizada em celulignina. A análise da Figura 5 ( $a, b, c)$ mostra que, após $48 \mathrm{~h}$, os diferentes ácidos testados conduziram a valores bastante similares de conversão do butanol (60,1 a 73,9\%). A conversão máxima foi alcançada para o sistema butanol e ácido octanóico $(73,9 \%)$ e a redução da conversão observada para o sistema butanol e ácido láurico (12 carbonos) pode sugerir um efeito negativo do tamanho da cadeia de carbônica, restringindo o acesso dos reagentes ao sítio ativo da enzima.

Efeitos similares têm sido descritos na literatura para diferentes derivados imobilizados de lipase, como por ex., para a preparação comercial de lipase imobilizada manufaturada pela Novozymes (Lipozyme). Segundo Miller et al. ${ }^{22}$, essa preparação de lipase tem como limitação substratos com um número superior de 15 carbonos, sendo estabelecido como sistema reacional mais adequado o sistema octanol e ácido heptanóico. Bruno et al. ${ }^{23}$ também verifi-
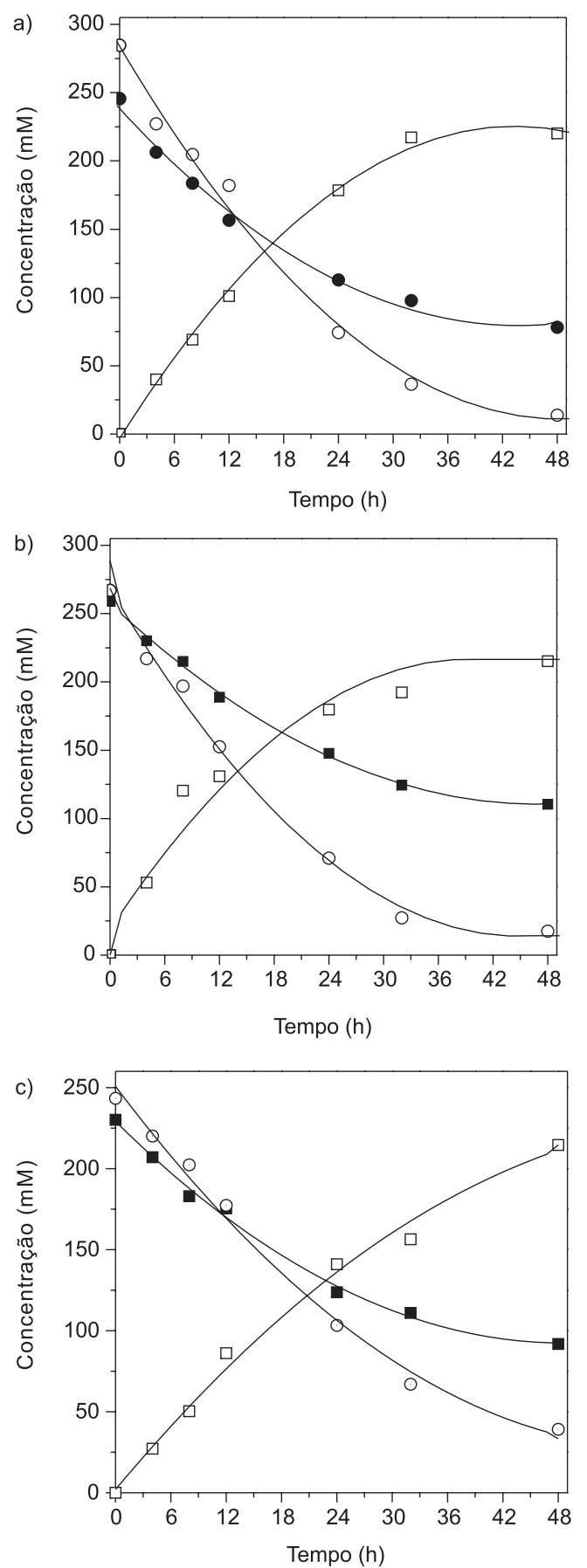

Figura 5. Influência do efeito do tamanho da cadeia carbônica do ácido carboxílico (○) na conversão do n-butanol (ם) aos ésteres correspondentes ( $\square$ ): butirato de n-butila (a), octanoato de n-butila (b) e laurato de n-butila (c) 
caram uma limitação na reação de síntese de ésteres catalisada pela lipase Mucor miehei imobilizada em matriz híbrida, constituída de polissiloxano e poli(álcool vinílico), para substratos compostos de álcoois e ácidos carboxílicos com cadeia superior a 14 carbonos. Nesse caso específico, o sistema composto de butanol e ácido octanóico foi o que apresentou conversão mais elevada ao éster correspondente.

Para verificar se essa limitação foi referente ao tamanho total de carbonos do substrato (álcool + ácido), ou mais especificamente ao tamanho da cadeia do ácido carboxílico (doador do grupo acila), foi também determinada a influência do tamanho da cadeia do álcool na síntese de ésteres derivados do ácido octanóico. Estes resultados são mostrados na Figura 6, que apresenta as porcentagens de consumo dos diferentes álcoois (etanol, propanol, butanol, hexanol e octanol) e do ácido octanóico em 48 h de reação.

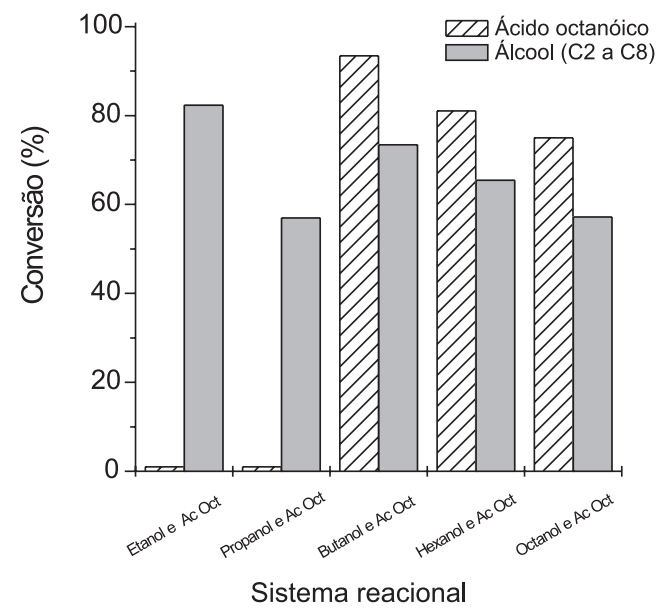

Figura 6. Influência do efeito do tamanho da cadeia carbônica do álcool na conversão dos materiais de partida aos ésteres correspondentes $\left(48 \mathrm{~h} \mathrm{a} 37^{\circ} \mathrm{C}\right)$

Com exceção dos ésteres octanoato de etila e de propila, os diferentes ésteres de octanoato foram obtidos com conversões superiores a $75 \%$, sendo ainda constatado consumo similar de ambos os materiais de partida. Nos sistemas reacionais constituídos por ácido octanóico e etanol ou propanol, não houve consumo do doador do grupo acila, apesar do aparente consumo total dos álcoois (etanol ou propanol). Esses resultados provavelmente devem-se aos elevados graus de volatilidade e polaridade desses álcoois, ocasionando dois efeitos: evaporação e/ou adsorção desses compostos no derivado imobilizado (migração ou partição do álcool para a parte sólida do meio reacional). Justificando, desta forma, o consumo aparente desses álcoois no meio reacional.

Com relação ao somatório do número de carbonos dos materiais de partida, observa-se mais uma vez que para substratos com número superior a 14 carbonos, ocorre uma redução gradativa da conversão molar do substrato no éster correspondente ${ }^{16,21}$.

A partir desses resultados, selecionou-se o sistema reacional constituído de ácido octanóico e $n$-butanol, para a determinação do perfil de estabilidade operacional deste preparado enzimático em meio orgânico.

\section{Testes de estabilidade}

\section{Estabilidade à estocagem}

Normalmente as enzimas imobilizadas mantêm sua atividade em condições de estocagem, quando não são expostas a condições adversas de $\mathrm{pH}$ e temperatura. A lipase imobilizada foi estocada a uma temperatura de $4{ }^{\circ} \mathrm{C}$ por 90 dias. Os resultados (Tabela 2) indicam que a atividade hidrolítica da lipase imobilizada em celulignina manteve-se estável por aproximadamente 30 dias. Após este período a atividade hidrolítica sofreu reduções significativas de 26,1 e $58,5 \%$ ao final de 60 e 90 dias de estocagem, respectivamente. Estes resultados são semelhantes aos obtidos na estocagem de uma preparação de lipase (Candida rugosa) imobilizada em palha de arroz, sugerindo que a redução da atividade enzimática pode estar relacionada com o tipo de suporte empregado (matriz derivada de material lignocelulósico).

Tabela 2. Atividades hidrolíticas da lipase imobilizada em celulignina em função do período de estocagem

\begin{tabular}{lcc}
\hline Período (dias) & $\begin{array}{c}\text { Atividade } \\
\text { hidrolítica }(\mathrm{U} / \mathrm{mg})\end{array}$ & $\begin{array}{c}\text { Atividade } \\
\text { residual }(\%)\end{array}$ \\
\hline Inicial & 133,70 & 100,00 \\
30 & 130,85 & 97,87 \\
60 & 98,78 & 73,88 \\
90 & 55,48 & 41,50 \\
\hline
\end{tabular}

\section{Estabilidade térmica}

Um aumento de temperatura geralmente corresponde a um aumento na taxa de reação por unidade de enzima. Entretanto, a elevação de temperatura e o tempo de exposição também podem promover aumento na taxa de desativação térmica da lipase, portanto, reduzindo a formação de produto. A Figura 7 apresenta a variação da atividade da lipase livre e imobilizada após tratamento térmico (40- $60{ }^{\circ} \mathrm{C}$ ) por $1 \mathrm{~h}$. Verifica-se que em pH 7,0 a $60{ }^{\circ} \mathrm{C}$, a lipase livre, após $1 \mathrm{~h}$ de incubação estava praticamente desnaturada, restando apenas 9\% de sua atividade inicial. Por outro lado, nessa mesma temperatura a enzima imobilizada ainda apresentou uma atividade relativa de $37 \%$, porém sua estabilidade térmica foi muito baixa, o que inviabiliza a utilização nesta temperatura por tempos superiores a $5 \mathrm{~min}$. A partir desses resultados calcularam-se as constantes de inativação térmica $\left(k_{d}\right)$ e o tempo de meia-vida $\left(\mathrm{t}_{1 / 2}\right)$ para a lipase livre e imobilizada (Tabela 3 ).

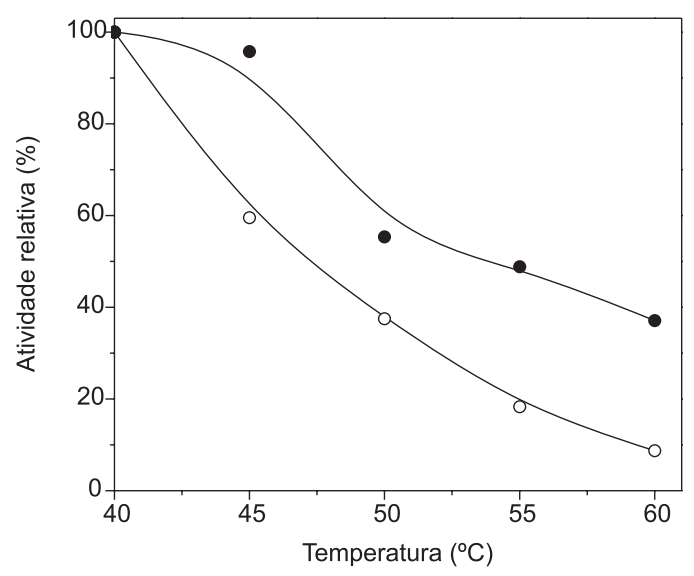

Figura 7. Estabilidade térmica da lipase livre $(\bigcirc)$ e imobilizada (○) após 1 $h$ de incubação nas temperaturas de $40-60{ }^{\circ} \mathrm{C}$

Os dados da Tabela 3 mostram que a perda de atividade catalítica para enzima livre é bem superior àquela determinada para a imobilizada a $45{ }^{\circ} \mathrm{C}$, sugerindo que o procedimento de imobilização em celulignina conferiu à lipase maior estabilidade térmica, apesar dos valores das constantes de inativação térmica tenderem para o 
Tabela 3. Constantes de inativação térmica da lipase livre e imobilizada em celulignina

\begin{tabular}{lcccc}
\hline Temperatura $\left({ }^{\circ} \mathrm{C}\right)$ & \multicolumn{2}{c}{$k_{\mathrm{d}}\left(\mathrm{h}^{-1}\right)$} & \multicolumn{2}{c}{ Tempo de meia-vida (h) } \\
\cline { 2 - 3 } & Lipase Livre & Lipase Imobilizada & Lipase Livre & 6,30 \\
\hline 45 & 0,52 & 0,11 & 1,33 & 0,88 \\
50 & 0,98 & 0,79 & 0,71 & 0,48 \\
65 & 1,69 & 1,45 & 0,41 & 0,34 \\
\hline
\end{tabular}

mesmo valor para temperaturas superiores a $50{ }^{\circ} \mathrm{C}$. Comportamentos similares têm sido observados para derivados imobilizados de lipase em suportes orgânicos ${ }^{24-26}$.

\section{Estabilidade operacional em meio aquoso}

A estabilidade operacional da lipase imobilizada em celulignina foi testada na reação de hidrólise do azeite de oliva $\left(30 \mathrm{~min} / 37{ }^{\circ} \mathrm{C}\right)$, conforme mostrado na Figura 8. A atividade lipolítica foi calculada ao final de cada ciclo, tomando por base a concentração de ácidos graxos formados, por g de biocatalisador, por minuto de reação. Para a estimativa do tempo de meia-vida do biocatalisador, as atividades relativas foram plotadas em função do tempo e por regressão linear obteve-se o tempo de meia-vida de 3,5 h.

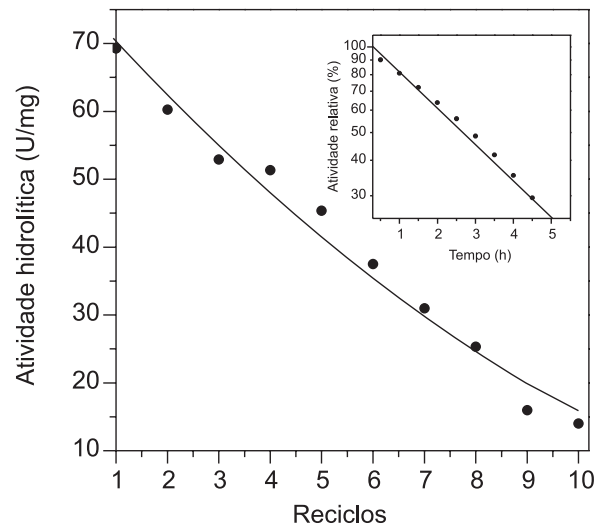

Figura 8. Estabilidade operacional da lipase imobilizada por ligação covalente em celulignina na hidrólise do azeite de oliva (ciclos de $30 \mathrm{~min} / 37^{\circ} \mathrm{C}$ )

Deve ser destacado que nas reações de hidrólise catalisadas por lipases imobilizadas, dessorções elevadas da enzima do suporte têm sido observadas ${ }^{23}$ (baixo tempo de meia-vida do biocatalisador). Esse efeito pode ser atribuído à presença de tensoativos (goma arábia, Triton $\mathrm{X}$, entre outros) normalmente usados no preparo dos substratos emulsificados, os quais geralmente facilitam a remoção da enzima fixada ao suporte (efeito de lixiviação). Apesar do sistema imobilizado ter apresentado limitações de uso em meio aquoso, isso não restringe sua aplicação em outras reações catalisadas pelas lipases, nas quais são utilizados substratos com baixo teor de água (meios não aquosos).

Estabilidade operacional da lipase imobilizada em meio orgânico

$\mathrm{O}$ estudo da estabilidade operacional da lipase imobilizada em celulignina foi realizado em regime de bateladas consecutivas $(48 \mathrm{~h} /$ $37{ }^{\circ} \mathrm{C} / 150 \mathrm{rpm}$ ). A atividade de esterificação do derivado imobilizado de lipase foi determinada pela formação do octanoato de butila na reação do ácido octanóico $(250 \mathrm{mmol})$ com n-butanol (250 mmol) em heptano, a $37{ }^{\circ} \mathrm{C}$, com massa seca de enzima igual a $0,5 \mathrm{~g}$. As concentrações finais do produto e dos materiais de partida em cada ciclo são mostradas na Figura 9. No final do primeiro ciclo, a concentração molar de octanoato de butila no meio reacional foi de $150 \mathrm{mmol}$, o que equivale a uma conversão molar de butanol de $60 \%$. Nas bateladas seguintes, a produção de éster alcançou concentrações médias de $110 \mathrm{mmol}$, com conseqüente redução da conversão molar de butanol para valores próximos de $56 \%$.

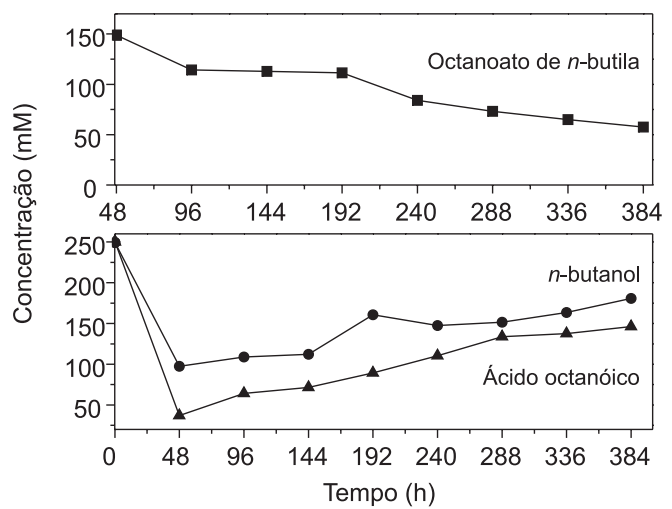

Figura 9. Perfis das concentrações de butanol (-) e ácido octanóico (\) na sintese de octanoato de n-butila (ם) catalisada pela lipase imobilizada em celulignina em bateladas consecutivas (ciclos de $48 \mathrm{~h} / 37^{\circ} \mathrm{C}$ )

Algumas oscilações desses valores foram observadas, devido às pequenas variações das concentrações iniciais dos materiais de partida presentes nos substratos empregados. De maneira geral, a lipase imobilizada manteve sua atividade original por $192 \mathrm{~h}$ (4 ciclos de 48 h) sendo constatada, após esse período, uma redução média na porcentagem de conversão dos reagentes de $40 \%$ e revelando um tempo de meia-vida de 302 h (Figura 10).

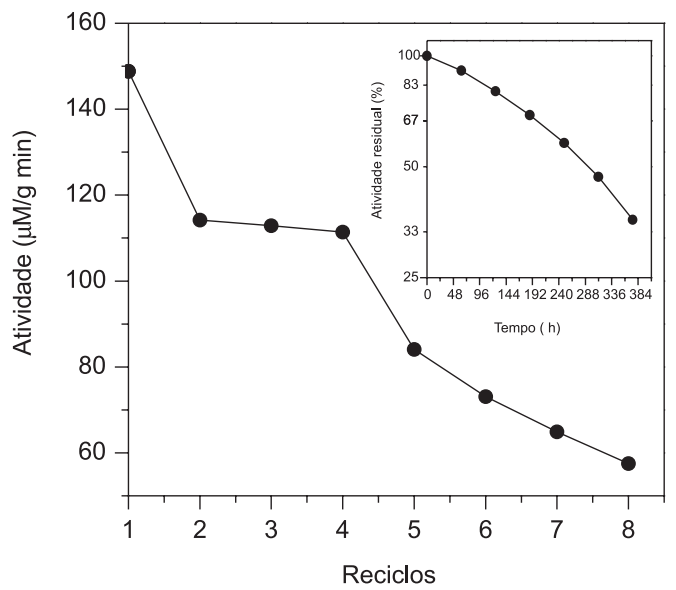

Figura 10. Estabilidade operacional da lipase imobilizada em celulignina na reação de esterificação do ácido octanóico com n-butanol em regime de bateladas consecutivas $\left(48 \mathrm{~h} / 37^{\circ} \mathrm{C}\right)$. 
Tabela 4. Propriedades catalíticas da lipase microbiana (Candida rugosa) imobilizada em diferentes suportes

\begin{tabular}{|c|c|c|c|c|c|c|c|}
\hline Característica & $\mathrm{SPC}$ & Quitosana & $\begin{array}{c}\text { Palha } \\
\text { de arroz }\end{array}$ & STY-DVB & Quitina & $\mathrm{ZrP}$ & Celulignina \\
\hline Método de imobilização & $\begin{array}{l}\text { Ligação } \\
\text { covalente }\end{array}$ & Adsorção & $\begin{array}{l}\text { Ligação } \\
\text { covalente }\end{array}$ & Adsorção & $\begin{array}{l}\text { Ligação } \\
\text { covalente }\end{array}$ & $\begin{array}{c}\text { Ligação } \\
\text { covalente }\end{array}$ & $\begin{array}{l}\text { Ligação } \\
\text { covalente }\end{array}$ \\
\hline Rendimento de imobilização (\%) & 18 & 17 & 82 & 42 & 26 & 60 & 64 \\
\hline Atividade da enzima (U/mg) & 51 & 51 & 180 & 110 & 60 & 287 & 193 \\
\hline pH ótimo & 7,5 & 6,0 & 7,0 & 7,5 & 7,5 & 7,5 & 8,0 \\
\hline Temperatura ótima $\left({ }^{\circ} \mathrm{C}\right)$ & 50 & 45 & 37 & 50 & 45 & 50 & 40 \\
\hline Inativação térmica a $50{ }^{\circ} \mathrm{C}\left(\mathrm{h}^{-1}\right)$ & 0,26 & 0,63 & 1,29 & nd & 1,07 & 0,37 & 0,79 \\
\hline \multicolumn{8}{|l|}{ Estabilidade operacional } \\
\hline Hidrólise $\left(\mathrm{t}_{1 / 2}\right.$ a $\left.37^{\circ} \mathrm{C}, \mathrm{h}\right)$ & 21 & 5,0 & 2,0 & nd & 3,3 & nd & 3,5 \\
\hline Esterificação $\left(\mathrm{t}_{1 / 2}\right.$ a $\left.37^{\circ} \mathrm{C}, \mathrm{h}\right)$ & 32 & 83 & nd & 620 & 426 & 412 & 302 \\
\hline Referência & 19 & 21 & 24 & 25 & 26 & 27 & Este trabalho \\
\hline
\end{tabular}

SPC: sílica de porosidade controlada; STY-DVB: copolímero de estireno-divinilbenzeno; ZrP: fosfato de zircônio; nd: não determinado

\section{Comparação das propriedades catalíticas da lipase de Candida rugosa imobilizada em diferentes suportes}

A imobilização de lipases em suportes orgânicos e inorgânicos, particularmente de lipase de Candida rugosa, tem sido descrita na literatura ${ }^{19,24-27}$. Para a melhor avaliação das propriedades obtidas pela amostra de lipase imobilizada em celulignina, na Tabela 4 são apresentados dados comparativos descritos para diversos derivados de lipase de Candida rugosa imobilizada.

Em termos de rendimentos de imobilização, a matriz testada nesse trabalho apresenta potencial comparável com outras matrizes orgânicas e inorgânicas, como copolímero de estireno-divinilbenzeno e fosfato de zircônio. Com relação à estabilidade térmica, o derivado imobilizado em celulignina foi superior às preparações obtidas em quitina, quitosana e muito superior ao derivado imobilizado em palha de arroz.

Com exceção da sílica de porosidade controlada, todos os derivados imobilizados obtidos apresentaram restrições para utilização em meio aquoso, o que não tem sido constatado em meio não aquoso. A estabilidade operacional da lipase imobilizada em celulignina apresentou um comportamento similar ao descrito para os demais derivados imobilizados de lipase, tornando atraente sua utilização como matriz de imobilização. Além disso, destaca-se o baixo custo de obtenção e a elevada densidade quando comparada com as outras matrizes de origem lignocelulósica, como por ex., palha de arroz.

\section{CONCLUSÕES}

A celulignina possui importantes propriedades físico-químicas, como porosidade e área superficial, que lhe conferem grande potencial para ser utilizada como matriz de imobilização de catalisadores bioquímicos. Em meio aquoso foi efetuado um estudo comparativo entre lipase livre e imobilizada em termos de $\mathrm{pH}$, temperatura e concentração de substrato. Foram observadas modificações no $\mathrm{pH}$ ótimo da enzima imobilizada para um $\mathrm{pH}$ básico $(8,0)$ e para valor mais elevado de temperatura $\left(40^{\circ} \mathrm{C}\right)$ quando comparadas com a enzima na sua forma livre $\left(\mathrm{pH}=7,0\right.$ a $\left.37^{\circ} \mathrm{C}\right)$. Os testes de estabilidade térmica revelaram que o derivado imobilizado apresentou maior estabilidade térmica que a lipase livre. Enquanto a lipase livre foi rapidamente desativada sob temperaturas superiores a $45^{\circ} \mathrm{C}$, a lipase imobilizada apresentou uma inativação térmica bem mais lenta nessas temperaturas. A influência da concentração do substrato na velocidade de reação permitiu deduzir um mecanismo cinético da reação e estimar os valores para $K_{m}(560,3$ para enzima livre e $924,8 \mathrm{mM}$ para o derivado imobilizado) e $V_{\max }$ (3937,6 para a enzima livre e 198,3 U/mg para o derivado imobilizado). Em meio orgânico, o derivado imobilizado foi aplicado satisfatoriamente na síntese de ésteres, empregando-se três tipos diferentes de álcoois (butanol, hexanol e octanol) e três tipos diferentes de ácidos orgânicos (ácido butírico, octanóico e láurico), e a única restrição foi referente ao uso do etanol e propanol como nucleófilos. A estabilidade operacional da enzima imobilizada em bateladas cíclicas em meio orgânico foi de 302 h, enquanto em meio aquoso foi de apenas 3,5 h. Essa diferença no comportamento da lipase imobilizada sugere uma limitação para aplicação do sistema imobilizado em reações de hidrólise.

\section{AGRADECIMENTOS}

Ao apoio financeiro concedido pela CAPES e CNPq e ao Departamento de Engenharia de Materiais da FAENQUIL pelo fornecimento de amostras de celulignina.

\section{REFERÊNCIAS}

1. Kazlauskas, R. J.; Bornscheuer, U. T. Em A Multi-Volume Comprehensive Treatise Biotechnology; Rehm, H. J.; Pihler G.; Stadler, A.; Kelly, P. J. W., eds.; Wiley VCH Verlag: New York, 1998, vol. 8.

2. Yahya, A. R. M.; Anderson, W. A.; Moo-Young, M.; Enzyme Microb. Technol. 1998, 23, 438.

3. Castro, H. F.; Mendes, A. A.; Santos, J. C.; Aguiar, C. L.; Quim. Nova 2004, $27,146$.

4. Aires-Barros, M. R.; Bol.Biotecnol. 2002, 72, 13.

5. Costa, V. E. U.; Amorim, H. L. N.; Quim. Nova 1999, 22, 120.

6. Halling, P. J.; Biotechnol. Bioeng. 1990, 35, 545.

7. Lima, A. W. O.; Agnes, L.; Quim Nova 1999, 22, 229.

8. Balcão, V. M.; Paiva, A. L.; Malcata, F. X.; Enzyme Microb.Technol. 1996, $18,392$.

9. Villeneuve, P.; Muderhwa, J. M.; Graille, J.; Haas, M. J.; J. Mol. Catal. B: Enzym. 2000, 9, 113.

10. Dalla-Vecchia, R.; Nascimento, M. G.; Soldi, V.; Quim Nova 2004, 27, 623.

11. Zanin, G. M.; Moraes, F. F. Em Enzimas como Agentes Biotecnológicos; Saiad, S.; Pietro, R. C. L. R., eds.; Legis Summa: Ribeirão Preto, 2004, cap. 4.

12. Tischer, W.; Kasche, V.; Trends Biotechnol. 1999, 17, 326.

13. Veliky, I. A.; Maclean, R. J.; Immobilized biosystems: Theoric and practical application, $1^{\text {st }}$ ed., Blackie Academic Professional: New York, 1994.

14. Pinatti, D. G.; Soares; A. G.; Vieira, C. A.; Rodrigues Jr., D.; Conte, R. A.; $6^{\circ}$ Brazilian Symposium of Chemistry Lignins and Wood Components, Guaratinguetá, Brasil, 2001.

15. Gomes, F. M.; Dissertação de Mestrado, Faculdade de Engenharia Química de Lorena, Brasil, 2003. 
16. Gomes, F. M.; Santos, G. S.; Conte, R. M.; Pinatti, D. G.; Castro, H. F.; Appl. Biochem. Biotechnol. 2005, 121/124, 255.

17. Akgöl, S.; Kaçar, Y.; Denizli, A.; Arica, M. Y.; Food Chem. 2001, 74, 281.

18. Carneiro-da-Cunha, M. G.; Rocha, J. M. S.; Cabral, J. M. S.; Gil, M. H.; Garcia, F. A. P.; Latin Am. App. Research 2002, 36, 69.

19. Soares, C. M. F.; de Castro, H. F.; Moraes, F. F.; Zanin, G. M.; Appl. Biochem. Biotechnol. 1999, 77, 745.

20. Muralidhar, R. V.; Chirumamilla, R. R.; Marchant, R.; Ramachandran, V. N.; Ward, O. P.; Nigam, P.; World J. Microbiol. Biotech. 2002, 18, 81

21. Pereira, E. B.; Zanin, G. M.; Castro, H. F.; Braz. J. Chem. Eng. 2003, 20, 343.
22. Miller, C.; Austin, H.; Posorske, L.; Gonzlez, J.; J. Am. Oil Chem. Soc. 1988, 65, 927.

23. Bruno, L. M.; Lima Filho, J. L.; Melo, E. H. M.; Castro, H. F.; Appl. Biochem. Biotechnol. 2004, 113/117, 189.

24. Freitas, L.; Mendes, A. A.; Castro, H. F.; Anais Assoc. Bras. Quim. 2003 , $52,124$.

25. Oliveira, P. C.; Alves, G. M.; Castro, H. F.; Bioch. Eng. J. 2000, 5, 63.

26. Gomes, F. M.; Pereira, E.B.; Castro, H. F.; Biomacromolecules 2004, 5 , 17.

27. Porto, T. F.; Silva, G. L. J.; Silva, M. L. C. P.; Castro, H. F.; Anais do XIV Congresso Brasileiro de Engenharia Química, Natal, Brasil, 2002. 